\title{
Influence of Bentall Procedure on Left Ventricular Function
}

Serkan Burç Deşer ${ }^{1}$, MD; Mustafa Kemal Demirag ${ }^{1}, M D ;$ Semih Murat Yucel ${ }^{1}$, MD; Ufuk Yildirim², MD; Murat Muzaffer Güçlü ${ }^{1}$, MD; Merve Polat ${ }^{1}$, MD; Fersat Kolbakir ${ }^{1}$, MD; Hasan Tahsin Keceligil ${ }^{1}$, MD

\section{Abstract}

Objective: To evaluate the influence of Bentall procedure on left ventricular function and condition on long-term follow-up.

Methods: Seventy-three consecutive patients who underwent an aortic root and ascending aorta replacement with composite valve button Bentall or flanged Bentall technique, from January 2007 to November 2018, were included in this retrospective study.

Results: Postoperative left ventricular ejection fraction significantly increased $(52.14 \pm 11.38$ vs. $56.79 \pm 11.36 ; P=0.041)$, left ventricular end-systolic diameter significantly reduced $(38.25 \pm 9.31$ $\mathrm{mm}$ vs. $34.17 \pm 9.15 \mathrm{~mm} ; P=0.027)$, left ventricular end-diastolic diameter significantly reduced $(56.42 \pm 9.72 \mathrm{~mm}$ vs. $51.58 \pm 9.03 \mathrm{~mm}$; $P=0.01)$, and left atrial diameter significantly reduced $(45.33 \pm 12.77$ $\mathrm{mm}$ vs. $39.25 \pm 12.41 \mathrm{~mm} ; \boldsymbol{P}=0.01$ ), compared to preoperative values.
Our long-term survival results are comparable with previous studies in which survival rates in 5 years and 10 years were $83.5 \%$ and $69.8 \%$, respectively. In comparing patients according to their New York Heart Association (NYHA) functional class, it was shown that their postoperative functional capacity was improved during the follow-up period $(2.1 \pm 0.56$ vs. $1.2 \pm 0.42 ; P=0.001)$.

Conclusion: The Bentall procedure significantly improved the left ventricular systolic function and condition and decreased the left ventricular end-systolic and end-diastolic diameters and the left atrial diameter on long-term follow-up, based on the transthoracic echocardiography. Bentall procedure can be performed with acceptable mortality and morbidity rates on long-term follow-up.

Keywords: Ventricular Function, Left. Survival Rate. Atrial Fibrilation. Aortic Valce. Echocardiography. Diastole. Aorta.

\begin{tabular}{ll}
\hline Abbreviations, acronyms \& symbols \\
\hline AVR & $=$ Aortic valve replacement \\
BMI & $=$ Body mass index \\
ICU & $=$ Intensive care unit \\
INR & $=$ International normalized ratio \\
LV & $=$ Left ventricular \\
LVEF & $=$ Left ventricular ejection fraction \\
NYHA & $=$ New York Heart Association \\
SD & $=$ Standard deviation \\
SPSS & $=$ Statistical Package for the Social Sciences
\end{tabular}

\section{INTRODUCTION}

The yearly incidence of mediastinal and thoracic aortic aneurysm is estimated to be about $4.5 / 100.000$ in total population and $60 \%$ of them are related to the aortic root and ascending aortic aneurysm ${ }^{[1]}$. Early surgery is recommended due to dissection or rupture risk ${ }^{[2]}$. Aortic root and valve replacement with a composite graft with a mechanical valve and coronary

'Department of Cardiovascular Surgery, School of Medicine, Ondokuz Mayis University, Samsun, Turkey.

${ }^{2}$ Department of Cardiology, School of Medicine, Ondokuz Mayis University, Samsun, Turkey.

This study was carried out at the Department of Cardiovascular Surgery, School of Medicine, Ondokuz Mayis University, Samsun, Turkey. artery reimplantation were first described in 1968 by Bentall and de Bono ${ }^{[3]}$. Since then, Bentall procedure has been the treatment of choice for aortic root with or without ascending aorta aneurysms, which improves clinics and hemodynamics of patients ${ }^{[3]}$. Button Bentall technique has been evolved and modified by Kouchoukos, as in 1981 [4]. David reimplantation ${ }^{[5]}$ and Sarsam and Yacoub remodeling techniques have been described as alternative valve sparing techniques ${ }^{[6]}$. Several modifications, such as button or flanged Bentall, were evolved to reduce bleeding, reduce coronary button tension, avoid kinking of coronary arteries, and reduce the time of surgery ${ }^{[3,7]}$. Coronary button separation, bleeding, and false aneurysm are the potential complications, which can be reduced with Cabrol procedure ${ }^{[8]}$. Mechanical valves are recommended for patients younger than 50 years old and bioprosthetic valves are recommended for patients older than 70 years old, which reduces the risk of thromboembolism, hemorrhage, and endocarditis. Besides that, the type of valve should be chosen regarding the expected survival, comorbidities, and risk of surgery ${ }^{[9]}$. Urgent Bentall procedure should be performed for

Correspondence Address:

Serkan Burç Deşer

(iD) https://orcid.org/0000-0001-9490-928X

Ondokuz Mayis Üniversitesi, Tıp Fakültesi, Kalp ve Damar Cerrahisi Ana Bilim Dalı, Atakum, Samsun/Turkey.

Zip Code: 55139

E-mail: sbd983@yahoo.com 
the diagnosis of acute type A aortic dissection, prosthetic graft infection, aortic valve endocarditis, and aortic abscess, while elective surgery should be performed for annuloaortic ectasia, aortic valve regurgitation, collagen tissue defects, such as Marfan syndrome, Loeys Dietz syndrome, Ehler Danlos syndrome, chronic type A aortic dissection, and post-stenotic dilatation ${ }^{[10,11]}$. Data regarding left ventricular (LV) function and condition after the Bentall procedure on long-term follow-up are scarce. In this retrospective study, we aimed to evaluate and analyze the left ventricular ejection fraction (LVEF) and condition after elective Bentall procedure on long-term follow-up.

\section{METHODS}

\section{Study Population}

Seventy-three consecutive patients who underwent aortic root with ascending aorta replacement with composite valve button Bentall or flanged Bentall technique, from January 2007 to November 2018, were included in this retrospective study (Figure 1). Perioperative risk factors, postoperative outcomes (stroke, bleeding, acute renal failure, etc.), 30-day operative mortality and mortality rates, mid-term and longterm survival, comorbidities (diabetes mellitus, hypertension, chronic obstructive pulmonary disease, coronary artery disease, Marfan syndrome, history of cardiac surgery, functional capacity, hyperlipidemia, chronic renal failure, etc.), need for concomitant procedures (i.e., coronary artery bypass grafting, mitral valve replacement, and hemiarch replacement), need for hypothermic circulatory arrest, overall in-hospital stay, intensive care unit
(ICU) Stay, and etiology were analyzed. All data including the demographic and clinical features of the patients were retrieved from the hospital's database. Of the 73 patients, long-term followup rate was $69.8 \%$ (51 patients). Physical examination, computed tomography scans, and transthoracic echocardiography were performed in all patients under follow-up. Patients with acute DeBakey type A aortic dissection and patients who underwent redo Bentall procedure were excluded. The presence of heart failure was defined in terms of the New York Heart Association (NYHA) functional classification. Clinical follow-up is performed every month with international normalized ratio (INR), and every six months with transthoracic echocardiography and computed tomography angiography. Table 1 summarizes the patients' preoperative variables and operative data.

\section{Surgical Method}

Flanged Bentall or button Bentall modification was performed in all patients (Figure 1). In the Bentall and de Bono buttontechnique, which was first described in $1968^{[3]}$, after the ascending aorta and aortic valve were resected, a composite graft was created with a mechanical aortic valve and a tubular graft was sutured. Then the composite graft was sutured to the aortic annulus with continuous polypropylene sutures. In the flanged Bentall procedure, which was first reported by Yakut in 2001 ${ }^{[12]}$, after approximately $5 \mathrm{~mm}$ of the end of the tubular graft is evaginated, the mechanical valve is sutured to the graft with continuous polypropylene sutures. Then the conduit was sutured to the aortic annulus from the everted part (flanged) of the graft with continuous polypropylene

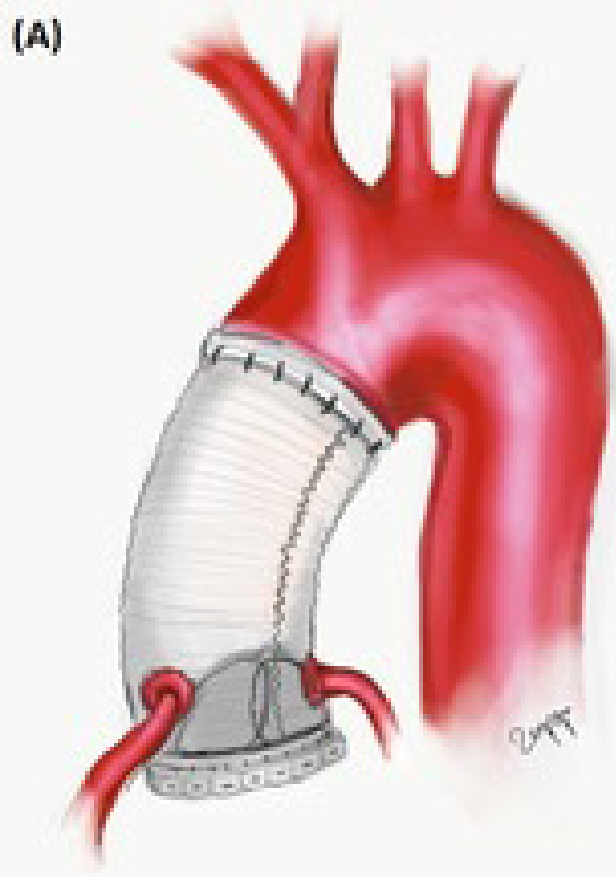

(B)

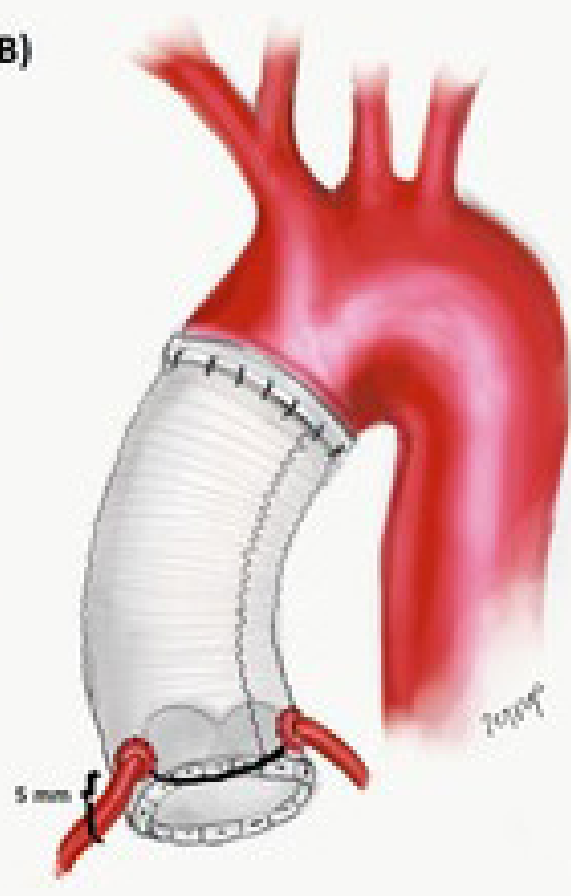

Fig. 1 - Depiction of button Bentall (A) and flanged Bentall (B) procedures. 
Table 1. Patients' preoperative variables and operative data.

\begin{tabular}{|c|c|c|}
\hline Preoperative variables and operative data & n (\%) & Mean \pm SD \\
\hline Age (years) & & $57.82 \pm 15.28$ \\
\hline Sex, male & $36(70.5)$ & \\
\hline Weight (kg) & & $74 \pm 9.8$ \\
\hline BMI & & $24.6 \pm 4.6$ \\
\hline Hypertension & $39(76.4)$ & \\
\hline Hyperlipidemia & $7(13.7)$ & \\
\hline Diabetes mellitus & $5(9.8)$ & \\
\hline Smoking & $10(19.6)$ & \\
\hline Chronic obstructive pulmonary disease & $6(11.7)$ & \\
\hline Coronary artery disease & $7(13.7)$ & \\
\hline Chronic renal disease & $2(3.9)$ & \\
\hline Bicuspid aortic valve & $5(9.8)$ & \\
\hline Marfan syndrome & $5(9.8)$ & \\
\hline Ejection fraction $<50 \%$ & $12(23.5)$ & \\
\hline Mechanical valve & $46(90.2)$ & \\
\hline Bioprosthetic valve & $5(9.8)$ & \\
\hline Composite valve size (mm) & $23.07 \pm 1.05$ & \\
\hline \multicolumn{3}{|l|}{ Concomitant cardiac procedures } \\
\hline Mitral valve replacement & $3(5.8)$ & \\
\hline Coronary artery bypass & $7(13.7)$ & \\
\hline Hemiarch replacement & $5(9.8)$ & \\
\hline
\end{tabular}

$\mathrm{BMI}=$ body mass index; SD=standard deviation

sutures (Figure 1). Distal anastomosis was performed with either closed or open technique, using hypothermic circulatory arrest alone or with selective antegrade or retrograde cerebral perfusion, according to the need. The partial cardiopulmonary bypass was instituted with ascending aortic cannulation or right axillary artery cannulation and two-stage venous cannulation via median sternotomy. Femoral cannulation was instituted in redo cases. Routine antegrade cardioplegia was used for the constituted diastolic arrest, then retrograde cardioplegia was used routinely to maintain the diastolic arrest and topical cooling was applied for myocardial protection. Deep hypothermic circulatory arrest $\left(18^{\circ} \mathrm{C}\right)$ was achieved with antegrade cerebral perfusion in selective cases and open clamp technique was performed for distal anastomosis. Both mechanical and bioprosthetic valves were used. The composite valve graft was created with Dacron tube graft and St. Jude valves (St. Jude Medical, Inc., St. Paul, Minnesota, USA), Carbomedics valve (Carbomedics, Austin, Texas, USA), or Sorin valves (Sorin, Milano, Italy), with a continuous 4-0 poly-fluoride vinyl suture. Of the 51 patients, 21-mm aortic valves with composite graft were implanted in six patients, $23-\mathrm{mm}$ aortic valves with composite graft were implanted in 37 patients, and 25-mm aortic valves with composite graft were implanted in eight patients. The mean sinotubular junction was $50.1 \pm 2.7 \mathrm{~mm}$. Proximal anastomosis was performed with pledgeted 3-0 polyester sutures, while distal anastomosis (4-0) and coronary button anastomoses (6-0) were performed with continuous poly-fluoride vinyl sutures. Postoperative low-molecular-weight heparin and warfarin sodium were administered to all patients. Anticoagulation was achieved with an INR between 2,5 and 3,5.

\section{Follow-Up}

Transthoracic echocardiographic examinations were performed with Vivid ${ }^{\circledR} 7$ (GE Healthcare, Waukesha, Wisconsin, USA) before surgery and two weeks, one, three, and six months after surgery, and then performed annually. For this study, the remaining 51 patients were called, and transthoracic echocardiography was performed by the same cardiologist with the same device Vivid ${ }^{\circledR} 7$ (GE Healthcare, Waukesha, Wisconsin, USA). LV end-systolic and end-diastolic diameters, LVEF (using a modified Simpson biplane formula), interventricular septum, pulmonary artery pressure, right ventricular diameter, left atrial diameter, and posterior wall diameter were calculated. Patients' functional statuses were defined on admission and after a mean 
period of 31 \pm 27.3 months (range 3-96 months) according to the NYHA functional classification. Overall survival was analyzed.

The study protocol was approved by the local ethics committee (OMU KAEK 2019/75). The study was carried out in accordance with the Helsinki Declaration principles.

\section{Statistical Analysis}

The Statistical Package for the Social Sciences software for Windows (SPSS Inc, Chicago, Illinois, USA), version 21, was used to compare the data. The Kolmogorov-Smirnov test was used to analyze normally distributed continuous variables. Categorical variables were presented in percentages and frequencies. The categorical data were tested with the Chi-square test or Fisher's exact test. Continuous variables were presented in mean \pm standard deviation (SD). The continuous variables were compared using the $t$-test and the Mann-Whitney $U$ test. Kaplan Meier test was performed for cumulative survival. A $P$-value of $<0.05$ was considered statistically significant.

\section{RESULTS}

\section{Sample Sizes and Demographic Features}

A total of 51 patients (36 males, 15 females; mean age $57.82 \pm 15.28$ years [range 14-90 years]) were followed up out of 73 patients who underwent aortic root with ascending aorta replacement with composite valve button Bentall or flanged Bentall technique; transthoracic echocardiography was performed. Of the 73 patients, the mean length of follow-up was 31 27,3 months (range 3-96 months) (Figure 2).

In the 51 patients, comparing to preoperative values, postoperative LVEF has significantly increased $(52.14 \pm 11.38 \mathrm{vs}$. 56.79 $\pm 11.36 ; P=0.041$ ), LV end-systolic diameter has significantly reduced (38.25 $\pm 9.31 \mathrm{~mm}$ vs. $34.17 \pm 9.15 \mathrm{~mm} ; P=0.027)$, LV enddiastolic diameter has significantly reduced $(56.42 \pm 9.72 \mathrm{~mm}$ vs. $51.58 \pm 9.03 \mathrm{~mm} ; P=0.01)$, and left atrial diameter has significantly reduced $(45.33 \pm 12.77 \mathrm{~mm}$ vs. $39.25 \pm 12.41 \mathrm{~mm} ; P=0.01)$, while postoperative right ventricular diameter has reduced $(29.25 \pm 4.57$ $\mathrm{mm}$ vs. $29.08 \pm 5.60 \mathrm{~mm} ; P=0.086$ ) without statistically significance (Table 2).

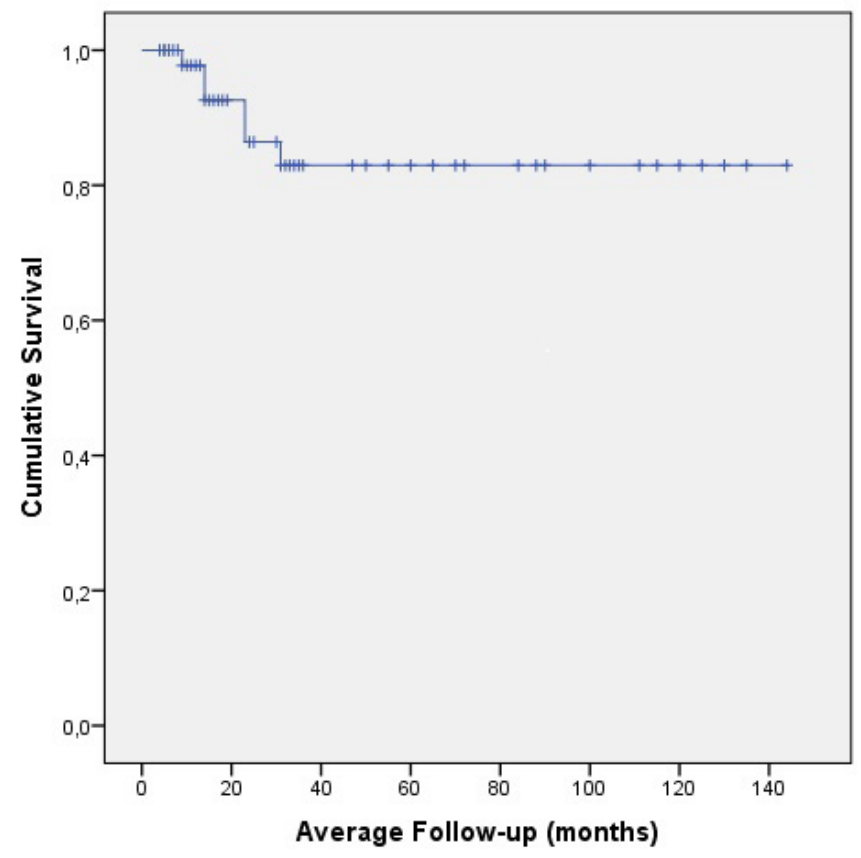

Fig. 2 - Cumulative survival rate of patients.

On contrast, postoperative pulmonary artery pressure (29.08 \pm 6.07 vs. $28.38 \pm 4.8 ; P=0.51)$, posterior wall diameter (12.58 $\pm 3.02 \mathrm{~mm}$ vs. $12.42 \pm 1.83 \mathrm{~mm} ; P=0.75)$, and interventricular septum ( $14.33 \pm 3.96 \mathrm{~mm}$ vs. $13.42 \pm 1.73 \mathrm{~mm} ; P=0.13$ ) have not significantly changed after index surgery.

Of the 73 patients, the overall early mortality (six patients), late mortality (six patients), and major stroke (two patients) rates were $8.3 \%, 8.3 \%$, and $2.8 \%$, respectively, and eight patients were out of follow-up.

Of the remaining 51 patients, five patients (9.8\%) underwent hemiarch replacement, postoperative bleeding was observed in five patients $(9.8 \%)$, and no thromboembolic complication was seen. All patients had aortic valve insufficiency, the annuloaortic ectasia with ascending aorta aneurysm was found to be the most common

Table 2. Comparison between preoperative and postoperative transthoracic echocardiographic parameters.

\begin{tabular}{l|c|c|c}
\hline & $\begin{array}{c}\text { Preoperative } \\
\text { Mean } \pm \text { SD }\end{array}$ & $\begin{array}{c}\text { Postoperative } \\
\text { Mean } \pm \text { SD }\end{array}$ & $P$-value \\
\hline Ejection fraction & $52.14 \pm 11.38$ & $56.79 \pm 11.36$ & 0.041 \\
\hline Left ventricular end-systolic diameter $(\mathrm{mm})$ & $38.25 \pm 9.31$ & $34.17 \pm 9.15$ & 0.027 \\
\hline Left ventricular end-diastolic diameter $(\mathrm{mm})$ & $56.42 \pm 9.72$ & $51.58 \pm 9.03$ & 0.01 \\
\hline Interventricular septum $(\mathrm{mm})$ & $14.33 \pm 3.96$ & $13.42 \pm 1.73$ & 0.13 \\
\hline Posterior wall diameter $(\mathrm{mm})$ & $12.58 \pm 3.02$ & $12.42 \pm 1.83$ & 0.75 \\
\hline Left atrial diameter $(\mathrm{mm})$ & $45.33 \pm 12.77$ & $39.25 \pm 12.41$ & 0.01 \\
\hline Right ventricular diameter $(\mathrm{mm})$ & $29.25 \pm 4.57$ & $29.08 \pm 5.60$ & 0.086 \\
\hline Pulmonary artery pressure & $29.08 \pm 6.07$ & $28.38 \pm 4.8$ & 0.51 \\
\hline SD & & &
\end{tabular}

$\mathrm{SD}=$ standard deviation 
etiology in our study (46 patients, 90.2\%) and the remaining five patients (9.8\%) had collagen tissue defects (Marfan syndrome). When we compared patients according to NYHA functional class, their postoperative functional capacity was improved during the follow-up period ( $2.1 \pm 0.56$ vs. $1.2 \pm 0.42 ; P=0.001$ ).

\section{DISCUSSION}

The main findings of the current study are that postoperative LVEF and NYHA functional class have significantly improved and postoperative LV end-systolic and end-diastolic diameters and left atrial diameter have significantly reduced during long-term follow-up.

Aortic root and valve replacement surgery has been applied since 1968 with reasonable low early/long-term follow-up, low mortality/morbidity rates, and improved long-term survival, in cases of annuloaortic ectasia, cystic medial necrosis, aortic aneurysm, and aortic dissection ${ }^{[3]}$. Aortic root replacement with composite graft is considered to be the choice of surgery for the diagnosis of ascending aorta aneurysm, annuloaortic ectasia, and aortic regurgitation ${ }^{[3,14]}$. The presence of Marfan syndrome, acute aortic dissection, endocarditis, redo surgery, urgent surgery, coronary artery disease, advanced age, low functional status, sudden cardiac death, congestive heart failure, stroke, chronic renal failure, and low cardiac output are considered to be indicators for early and late mortality rates ${ }^{[15,16]}$.

The reported mortality rate for elective Bentall surgery ranges from 1 to $5 \%{ }^{[17,18]}$. In addition, Pacini et al. ${ }^{[15]}$ reported a $6.9 \%$ early-term mortality rate. Dhurandhar et al. ${ }^{[1]}$ reported an overall $5.9 \%$ early mortality rate (30 days) and a 3.6\% elective surgery mortality. Furthermore, Pacini et al. ${ }^{[15]}$ reported a 274-patient study in that composite valve graft replacement was performed with a $6.9 \%$ early mortality rate. Mataraci et al.. ${ }^{[14]}$ reported that the early mortality rate was $11.8 \%$ and the late mortality rate was $2.8 \%$. We found similar results to those in our study, that early mortality rate was $8.3 \%$ and the late mortality rate was also $8.3 \%$.

Hagl et al. ${ }^{[19]}$ reported mid/long-term results after Bentall procedure: overall survival rates in five years and eight years were $95 \%$ and $93 \%$, respectively. Mataraci et al. ${ }^{[14]}$ reported longterm results of 254 patients: overall survival rates in one, three, and five years were $88.4 \%, 87.4 \%$, and $84.5 \%$, respectively, which was directly affected by the diagnosis of Marfan syndrome. Dhurandhar et al. ${ }^{[1]}$ reported that the overall survival rate was $84.4 \%$ in five years and $68.7 \%$ in 10 years. Pacini et al. ${ }^{[15]}$ reported five-year and 10-year survival rates as $77.7 \%$ and $63 \%$, respectively. Patients with Marfan syndrome have a higher probability of redo surgery for residual aortic dilatation than those without Marfan syndrome (94.6\% vs. $79.6 \%$ at 10 -year follow-up, $P=0.008)^{[20]}$. Our long-term survival results are comparable with previous studies: survival rates in five years and 10 years were $83.5 \%$ and $69.8 \%$, respectively. Aortic dissection negatively affects the survival among patients who underwent aortic root replacement ${ }^{[21]}$, and for this reason aortic root replacement can be negligible during acute aortic dissection ${ }^{[15,21]}$.

Dhurandhar et al. ${ }^{[1]}$ reported that the most common etiology of patients who underwent Bentall procedure was congenital bicuspid aortic valves (28.3\%), besides that, Marfan syndrome and annuloaortic ectasia constituted 19.3\%.
Mataraci et al. ${ }^{[14]}$ reported that postoperative low cardiac output was revealed as the main etiology for in-hospital mortality (51.4\%); in addition, they concluded that Marfan syndrome was the most common etiology, which affects the late mortality. However, there is no consensus on the influence of Marfan syndrome on long-term survival.

Patients with low ejection fraction may avoid aortic arch replacement. In the course of cooling and heating the patient during cardiopulmonary bypass, the total duration of the operation extends two hours, so the duration of myocardial ischemia increases. For this reason, there is a possibility of difficulty during weaning from the cardiopulmonary bypass, and length of ICU stay may increase.

Most of the studies investigated the surgical techniques and alterations, however, studies which investigate the LV function and condition on mid/long-term follow-up after the Bentall procedure are scarce. Dkojic et al.. ${ }^{[12]}$ reported that long-term LV systolic function had been improved, and that LV mass was reduced after the Bentall procedure in patients who underwent elective surgery. Nardi et al. ${ }^{[22]}$ reported that LV function and LV end-diastolic diameter were significantly improved after the Bentall procedure in patients diagnosed with Marfan syndrome. Djokic et al..'12] reported that LV mass was significantly reduced eight years after the Bentall procedure. Some authors advocated that Bentall procedure improves functional capacity in the long-term period ${ }^{[23]}$. LV systolic function was significantly increased and LV mass was significantly reduced after the Bentall procedure ${ }^{[13]}$.

Tanoue et al.. ${ }^{[13]}$ investigated the LV performance after aortic valve replacement (AVR) in 263 patients with three parameters, such as contractility, efficiency, and ejection fraction. They found out that afterload and LV contractility were reduced in patients diagnosed with aortic valve stenosis, while they were increased in patients diagnosed with aortic valve regurgitation after AVR. However, LV efficiency was deteriorated in patients diagnosed with aortic regurgitation due to impaired LV function, albeit LV efficiency was ameliorated after AVR in patients diagnosed with both aortic valve stenosis and aortic valve stenosis-regurgitation. Furthermore, they demonstrated that the ejection fraction was significantly reduced after AVR in all patients ${ }^{[13]}$. In addition, LV volume reduced after AVR in patients with aortic valve regurgitation, which leads to ventricular contractility. Despite all these results, they concluded that LV contractility and efficiency were excellent and satisfactory after AVR during mid-term follow-up.

In another study, which was also conducted by Tanoue et al[.[24], 15 patients with annuloaortic ectasia with aortic regurgitation underwent Bentall surgery. They revealed that contractility and afterload were augmented and LV efficiency was significantly improved after Bentall procedure on mid-term follow-up.

Djokic et al. ${ }^{[12]}$ reported that patients with annuloaortic ectasia were more prone to be operated earlier than those without it. Sinus Valsalva influenced the hydrodynamic of native aortic valve leaflet motion ${ }^{[24]}$. Djokic et al. ${ }^{[12]}$ conducted a study with 90 patients who underwent elective Bentall procedure and investigated the LV systolic function, volume, and mass in the long-term period. They revealed that LV systolic function 
was increased while LV mass was reduced after the Bentall procedure on long-term follow-up (mean $117 \pm 41$ months). Of those 90 patients, 66 patients were alive and four patients with acute myocardial infarction, four patients with heart failure, two patients with acute aortic dissection, and 13 patients with noncardiac causes passed away during follow-up.

Jiang et al. ${ }^{25]}$ reported that the mean LV end-diastolic diameter reduced, while ejection fraction was increased after Bentall procedure in six patients. Our study shows similar results to those: postoperative LVEF was increased and LV end-systolic and end-diastolic diameters and left atrial diameter were significantly reduced after index surgery.

In addition, flanged Bentall technique is presumed to be an effective way to decrease postoperative bleeding from proximal anastomosis, and the flexibility and elasticity of the aortic annulus can be preserved, which reduces the tension. The advantage of mechanical composite valved graft is durability and it reduces reoperations due to aortic valve insufficiency ${ }^{[25]}$. The advantages of valve-sparing procedures, such as David reimplantation and Yacoub remodeling techniques, are avoiding anticoagulation therapy and reducing mechanical valve endocarditis and longterm risk of anticoagulation therapy ${ }^{[26]}$. However, no difference was found in terms of ventricular function and LV end-diastolic volume between these techniques. The mortality rate of patients with mechanical valve was found to be higher at the 10-year follow-up period, although there was no difference in mortality in their 5-year follow-up ${ }^{[26,29]}$.

In our experience and surgical notion, we believe that flanged procedure provides lower anastomatic hemorrhage and pseudoaneurysm than button procedure, and that internal organs are better preserved at $18^{\circ} \mathrm{C}$. We did not dare to cool down below $18^{\circ} \mathrm{C}$ due to further elongation of surgery to prevent and reduce the destruction of blood cells as much as possible.

This study has a number of limitations worth noting. Firstly, we conducted a retrospective study, including patients who underwent flanged or button Bentall procedure and some factors may have changed during long-term follow-up. Secondly, the number of patients included in our study may be relatively small compared to other studies. Thirdly, it's a singlecenter design. Fourthly, only diameters and ejection fraction values were available, except ventricular volumes and LV mass, in this retrospective study. And finally, the effect of drugs was not examined on LV function.

\section{CONCLUSION}

The Bentall procedure significantly improved LV systolic function and condition and decreased LV end-systolic and enddiastolic diameters and left atrial diameter on long-term followup, based on the transthoracic echocardiography. The Bentall procedure can be performed with reasonable mortality and morbidity rates on long-term follow-up.

\section{No financial support. No conflict of interest.}

\section{Authors' roles \& responsibilities \\ SBD Writing, design, analysis; final approval of the version to be published \\ MKD Substantial contributions to the conception or design of the work; final approval of the version to be published \\ SMY Interpretation of data for the work; final approval of the version to be published \\ UY The acquisition; final approval of the version to be published \\ MMG Substantial contributions to the conception or design of the work; final approval of the version to be published \\ MP Substantial contributions to the conception or design of the work; final approval of the version to be published \\ FK Writing; final approval of the version to be published \\ HTK Analysis; final approval of the version to be published}

\section{REFERENCES}

1. Dhurandhar V, Parikh R, Saxena A, Vallely MP, Wilson MK, Black DA, et al. The aortic root replacement procedure: 12-year experience from the Australian and New Zealand society of cardiac and thoracic surgeons database. Heart Lung Circ. 2016;25(12):1245-51. doi:10.1016/j. hlc.2016.04.014.

2. Nataf P, Lansac E. Dilation of the thoracic aorta: medical and surgical management. Heart. 2006;92(9):1345-52. doi:10.1136/hrt.2005.074781.

3. Bentall $\mathrm{H}$, De Bono A. A technique for complete replacement of the ascending aorta. Thorax. 1968;23(4):338-9. doi:10.1136/thx.23.4.338.

4. Kouchoukos NT, Wareing TH, Murphy SF, Perrillo JB. Sixteen-year experience with aortic root replacement. Results of 172 operations. Ann Surg. 1991;214(3):308-20; discussion 318-20. doi:10.1097/00000658$199109000-00013$.

5. David TE. Aortic valve sparing operations: outcomes at 20 years. Ann Cardiothorac Surg. 2013;2(1):24-9. doi:10.3978/j.issn.2225319X.2012.11.15.

6. Sarsam MA, Yacoub M. Remodeling of the aortic valve anulus. JThorac Cardiovasc Surg. 1993;105(3):435-8.

7. Yakut C. A new modified Bentall procedure: the flanged technique. Ann Thorac Surg. 2001;71(6):2050-2. doi:10.1016/s0003-4975(01)02439-0.

8. Etz CD, Homann TM, Rane N, Bodian CA, Di Luozzo G, Plestis KA, et al. Aortic root reconstruction with a bioprosthetic valved conduit: a consecutive series of 275 procedures. J Thorac Cardiovasc Surg. 2007;133(6):1455-63. doi:10.1016/j.jtcvs.2007.01.058.

9. Elefteriades JA. Natural history of thoracic aortic aneurysms: indications for surgery, and surgical versus nonsurgical risks. Ann Thorac Surg. 2002;74(5). S1877-80 ; discussion S1892-8. doi:10.1016/s00034975(02)04147-4.

10. Cabrol C, Pavie A, Gandjbakhch I, Villemot JP, Guiraudon G, Laughlin L, et al. Complete replacement of the ascending aorta with reimplantation of the coronary arteries: new surgical approach. J Thorac Cardiovasc Surg. 1981;81(2):309-15.

11. Dossche $K$, Schepens $M$, Morshuis W, de la Rivière $A B$, Knaepen PJ, Vermeulen FE. A 23-year experience with composite valve graft replacement of the aortic root. Ann Thorac Surg. 1999;67(4):1070-7. doi:10.1016/s0003-4975(99)00162-9.

12. Djokic O, Otasevic P, Micovic S, Tomic S, Milojevic P, Boskovic S, et al. Effect of elective Bentall procedure on left ventricular systolic function 
and functional status: long-term follow-up in 90 patients. Tex Heart Inst J. 2016:43(2):114-8. doi:10.14503/THIJ-14-4127.

13. Tanoue Y, Maeda T, Oda S, Baba H, Oishi Y, Tokunaga S, et al. Left ventricular performance in aortic valve replacement. Interact Cardiovasc Thorac Surg. 2009;9(2):255-9. doi:10.1510/icvts.2009.202309.

14. Mataraci I, Polat A, Kiran B, Caliskan A, Tuncer A, Erentug V, et al. Longterm results of aortic root replacement: 15 years' experience. Ann Thorac Surg. 2009;87(6):1783-8. doi:10.1016/j.athoracsur.2009.03.046.

15. Pacini D, Ranocchi F, Angeli E, Settepani F, Pagliaro M, Martin-Suarez S, et al. Aortic root replacement with composite valve graft. Ann Thorac Surg. 2003;76(1):90-8. doi:10.1016/s0003-4975(03)00265-0.

16. Etz CD, Bischoff MS, Bodian C, Roder F, Brenner R, Griepp RB, et al. The Bentall procedure: is it the gold standard? a series of 597 consecutive cases. JThorac Cardiovasc Surg. 2010;140(6 Suppl):S64-70 ; discussion S86-91. doi:10.1016/j.jtcvs.2010.07.033.

17. Hiratzka LF, Bakris GL, Beckman JA, Bersin RM, Carr VF, Casey DE Jr, et al. 2010 ACCF/AHA/AATS/ACR/ASA/SCA/SCAI/SIR/STS/SVM guidelines for the diagnosis and management of patients with thoracic aortic disease. J Am Coll Cardiol. 2010;55(14):e27-129. Erratum in: J Am Coll Cardiol. 2013;62(11):1039-40. doi:10.1016/j.jacc.2010.02.015.

18. Tamura K, Arai H, Kawaguchi S, Makita S, Miyagi N, Watanabe T, et al. Long-term results of modified Bentall procedure using flanged composite aortic prosthesis. Ann Thorac Cardiovasc Surg. 2013;19(2):12630. doi:10.5761/atcs.oa.12.01943.

19. Hagl C, Strauch JT, Spielvogel D, Galla JD, Lansman SL, Squitieri R, et al. Is the Bentall procedure for ascending aorta or aortic valve replacement the best approach for long-term event-free survival? Ann Thorac Surg. 2003;76(3):698-703; discussion 703. doi:10.1016/s0003-4975(03)00568-X.

20. Gott VL, Gillinov AM, Pyeritz RE, Cameron DE, Reitz BA, Greene PS, et al. Aortic root replacement. Risk factor analysis of a seventeen-year experience with 270 patients. JThorac Cardiovasc Surg. 1995;109(3):53644; discussion 544-5. doi:10.1016/S0022-5223(95)70286-5.

21. Niederhäuser U, Rüdiger H, Vogt P, Künzli A, Zünd G, Turina M. Composite graft replacement of the aortic root in acute dissection. Eur J Cardiothorac Surg. 1998;13(2):144-50. doi:10.1016/s1010-7940(97)00311-4.

22. Nardi P, Pellegrino A, Versaci F, Mantione L, Polisca P, lorio FS, et al. Aortic root surgery in Marfan syndrome: Bentall procedure with the composite mechanical valved conduit versus aortic valve reimplantation with Valsalva graft. J Cardiovasc Med (Hagerstown). 2010;1 1(9):648-54. doi:10.2459/JCM.0b013e3283379998.

23. Bhan A, Choudhary SK, Saikia M, Sharma R, Venugopal P. Surgical experience with dissecting and nondissecting aneurysms of the ascending aorta. Indian Heart J. 2001;53(3):319-22.

24. Tanoue Y, Tornita Y, Morito S, Tominaga R. Ventricular energetics in aortic root replacement for annuloaortic ectasia with aortic regurgitation. Heart Vessels. 2009;24(1):41-5. doi:10.1007/s00380-008-1076-3.

25. Jiang SL, Li BJ, Gao CQ, Ren CL, Wang Y, Cheng TT, et al. [Clinical analyses of cardiovascular operations in patients with severe dilated left ventricle]. Zhonghua Yi Xue Za Zhi. 2010;90(42):2999-3002. Chinese.

26. Aortic Stenosis Writing Group, Bonow RO, Brown AS, Gillam LD, Kapadia SR, Kavinsky CJ, et al. ACC/AATS/AHA/ASE/EACTS/HVS/SCA/SCAI/ SCCT/SCMR/STS 2017 appropriate use criteria for the treatment of patients with severe aortic stenosis: a report of the American college of cardiology appropriate use criteria task force, American association for thoracic surgery, American heart association, American society of echocardiography, European association for cardio-thoracic surgery, heart valve society, society of cardiovascular anesthesiologists, society for cardiovascular angiography and interventions, society of cardiovascular computed tomography, society for cardiovascular magnetic resonance, and society of thoracic surgeons. J Am Soc Echocardiogr. 2018;31(2):11747. doi:10.1016/j.echo.2017.10.020.

27. Borowski A, Ghodsizad A, Vchivkov I, Gams E. Surgery for severe aortic stenosis with low transvalvular gradient and poor left ventricular function - a single centre experience and review of the literature. J Cardiothorac Surg. 2007;2:9. doi:10.1186/1749-8090-2-9.

28. Ergün S, Dedemoğlu M, Rabuş MB, Özbek B, Özgür MM, Tuncer MA, et al. Short-term results of flanged Bentall de Bono and valve-sparing David $\checkmark$ procedures for the treatment of aortic root aneurysms. Cardiovasc J Afr. 2018;29(4):241-5. doi:10.5830/CVJA-2018-021.

29. Lamana F de A, Dias RR, Duncan JA, Faria LB, Malbouisson LM, Borges L de F, et al. Surgery of the aortic root: should we go for the valve-sparing root reconstruction or the composite graft valve replacement is still the first choice of treatment for these patients? Rev Bras Cir Cardiovasc. 2015;30(3):343-52. doi:10.5935/1678-9741.20150028. 